\title{
Lack of effect of hormones and inducers of intracellular messengers on plasminogen activator production by bovine embryos in vitro
}

\author{
A. Al-Hozab and A. R. Menino, Jr* \\ Department of Animal Sciences, Oregon State University, Corvallis, OR 97331-6702, USA
}

\begin{abstract}
Summary. Several hormones and inducers of intracellular messengers, known to affect plasminogen-activator (PA) production in other systems, were investigated for putative effects on bovine embryos. Day 8 embryos were cultured for 5 days in a humidified atmosphere of $5 \% \mathrm{CO}_{2}$ in air at $37^{\circ} \mathrm{C}$ in media containing different concentrations of progesterone, oestradiol, dexamethasone, retinoic acid, dibutyryl cyclic AMP (dbcAMP) and phorbol myristate acetate (PMA). At intervals of $24 \mathrm{~h}$, the medium was recovered for PA analysis and overall embryonic diameter was measured. While none of the hormones and agents tested affected PA production $(P>0.05)$, dimethyl sulfoxide, which was used to dissolve PMA, inhibited PA production during the first $72 \mathrm{~h}$ of culture $(P<0.05)$. PA production was affected by duration of culture $(P<0.05)$. Concentrations of plasminogen activator in the media were low during the first $48 \mathrm{~h}$, had increased after 72 and $96 \mathrm{~h}$ in culture, and either remained high or decreased slightly toward the end of the culture period. With the exceptions of dbcAMP and PMA, the hormones tested in this study did not affect embryonic size. Dibutyryl cAMP caused a progressive decrease in embryonic diameter. PMA resulted in embryo death at high concentrations but at lower concentrations it enhanced overall embryonic diameter throughout the time of culture $(P<0.05)$. These results suggest that cultured bovine embryos produce PA in a fixed, time-dependent manner, independent of exogenous hormonal regulation.
\end{abstract}

Keyrords: embryo; plasminogen activator; hormones; cow

\section{Introduction}

Plasminogen activators (PA) are serine proteases that convert the zymogen plasminogen to the active protease plasmin by the cleavage of an Arg-Val peptide bond. Two types of PA have been identified by functional differences, relative molecular mass $\left(M_{\mathrm{r}}\right)$, and immunological activities: urokinase-type (UPA) and tissue-type (tPA) with $M_{\mathrm{r}}$ of $30-55 \times 10^{3}$ and $70 \times 10^{3}$, respectively (Dano et al., 1985). It has been suggested that uPA participates in localized proteolysis of the extracellular matrix accompanying tissue remodelling and cellular migration (Blasi et al., 1987). Tissue-type PA displays a high affinity for fibrin and is therefore considered as the key enzyme in thrombolysis (Astrup, 1978).

As well as being present in many types of normal and malignant cells, PA are produced by the embryos of mice (Strickland et al., 1976), rats (Liedholm \& Astedt, 1975), pigs (Mullins et al., 1980), cattle (Menino \& Williams, 1987) and sheep (Menino et al., 1989). Although the exact function of PA in early embryonic development is not known, it has been implicated in the migration of parietal endodermal cells and in the implantation in mouse embryos (Sherman et al., 1976; Strickland et al., 1976; Sherman, 1980; Axelrod, 1985; Sappino et al., 1989), tissue 
remodelling and proliferation in pig embryos (Fazleabas et al., 1983), and embryo hatching in cattle and sheep (Menino \& Williams, 1987; Menino et al., 1989).

The extracellular proteolytic activity of the PA system is regulated by a delicate balance between PA, plasminogen and their endogenous inhibitors. Several agents have been shown to modulate plasminogen activation in a variety of cells. Gonadotrophins stimulate PA activity in rat granulosa cells (Strickland \& Beers, 1976; Reich et al., 1985; Canipari \& Strickland, 1986), in cultured human cytotrophoblasts (Queenan et al., 1987), and in rat and bovine Sertoli cells (Lacroix et al., 1981; Marzowski et al., 1985; Hettle et al., 1986; Coombs et al., 1988). The effects of gonadotrophins are assumed to be mediated by cyclic adenosine monophosphate (cAMP). Oestrogen stimulates the production of PA in human breast carcinoma cell lines (Dickerman et al., 1989) and enhances plasminogen uptake by the mouse uterus (Finlay et al., 1983). Glucocorticoids, such as dexamethasone, inhibit PA activity in rat granulosa cells (Harlow et al., 1987) and in bovine Sertoli cells (Coombs \& Jenkins, 1988) by stimulating the production of PA-inhibitors (PAI). Similarly, progesterone was found to stimulate the production of protease inhibitors in mouse and pig uteri (Harpel et al., 1966; Mullins et al., 1980); thus inhibiting fibrinolytic activity within the uterus during specific stages of the oestrous cycle. Phorbol myristate acetate (PMA) and retinoic acid are also potent inducers of PA production in a number of different cells and tissues (Strickland \& Mahdavi, 1978; Wilson \& Reich, 1978; Opdenakker et al., 1983; Santell \& Levin, 1988).

Hormonal regulation of embryonic PA production has not been studied. This research evaluated the effects of progesterone, oestradiol, dexamethasone, retinoic acid, dibutyryl cAMP (dbcAMP) and PMA on PA production in cultured bovine embryos. Changes in embryonic size were also studied to assess embryo viability in response to the hormonal treatments.

\section{Materials and Methods}

\section{Embryo collection and culture}

Thirty-two crossbred beef cows from the Oregon State University beef herd were treated with prostaglandin $F_{2 u}$ $\left(\mathrm{PGF}_{2 a}\right.$; Lutalyse: The Upjohn Co., Kalamazoo, MI) to synchronize oestrus and with porcine follicle-stimulating hormone (pFSH; Schering Corp., Kenilworth, NJ) to induce superovulation. Two $25 \mathrm{mg}$ injections of PGF $2 a$ were administered i.m. 14 days apart (day $0=$ first PGF $_{2 a}$ injection) to all cows. Porcine follicle-stimulating hormone injections were administered twice a day i.m. at doses of 5, 4, 2 and $1 \mathrm{mg}$ on days $12,13,14$ and 15 , respectively. Oestrus detection was initiated $24 \mathrm{~h}$ after the second $\mathrm{PGF}_{2 \mathrm{u}}$ injection. Cows were either mated naturally at the onset of oestrus and at $12 \mathrm{~h}$ intervals thereafter, or artificially inseminated at 0,12 and $24 \mathrm{~h}$ after onset of oestrus using one straw of frozen semen each time.

Embryos were collected 8 days after mating either nonsurgically or at death. In the nonsurgical collection, uteri were flushed with Dulbecco's phosphate-buffered saline (Dulbecco \& Vogt, 1954) containing $0 \cdot 5 \%$ bovine serum albumin (BSA; Sigma, St Louis, MO) and $10 \mathrm{ml} \mathrm{l}^{-1}$ of an antibiotic-antimycotic solution ( 10000 units penicillin, $10 \mathrm{mg}$ streptomycin and $25 \mu \mathrm{g}$ amphotericin B per $\mathrm{ml}$ in $0.9 \%$ sodium chloride; Sigma). Excised uteri removed at death were flushed with Ham's F-12 containing $10 \mathrm{ml} \mathrm{l}^{-1}$ of the antibiotic-antimycotic solution (Sigma). Embryos were recovered from the flushings under a dissecting microscope, washed at least three times in microdrops of Ham's F-12 with either 15 or $1.5 \mathrm{mg} \mathrm{BSA} \mathrm{ml}{ }^{-1}$, and morphologically evaluated using an inverted-stage, phase-contrast microscope. Only morphologically normal embryos were assigned to the various hormonal treatments (Lindner \& Wright, 1983). Embryos were individually cultured in $35 \mu \mathrm{l}$ microdrops under paraffin oil (Fisher Scientific Co., Tustin, CA) in a humidified atmosphere of $5 \% \mathrm{CO}_{2}$ in air at $37^{\circ} \mathrm{C}$ for 5 days. At the initiation of culture and at subsequent $24 \mathrm{~h}$ intervals, embryonic cell stage was recorded and overall embryonic diameter (OED) was measured using an ocular micrometer. At $24 \mathrm{~h}$ intervals, embryos were transferred to fresh microdrops and $15 \mu \mathrm{l}$ of the culture medium were recovered and frozen at $-20^{\circ} \mathrm{C}$ until assayed for PA activity. Another $15 \mu \mathrm{l}$ of medium from a microdrop without an embryo was recovered for every treatment to correct for any spontaneous activation of plasminogen.

\section{Effect of hormones and inducers of intracellular messengers on PA production and OED by cultured bovine embryos}

In treatments where hormones and intracellular messengers were dissolved in absolute ethanol or dimethyl sulfoxide (DMSO), appropriate stocks and dilutions were formulated so that the percentages of solvent in the media were the same for all concentrations within a treatment. Appropriate vehicle controls were used for each treatment. When possible, for a given hormone or intracellular messenger, embryos from the same donor cows were allocated randomly to each treatment. 


\section{Progesterone}

Progesterone (Sigma) was initially dissolved in absolute ethanol and diluted further to final concentrations of $10^{-8}, 10^{-7}$ and $10^{-6} \mathrm{~g} \mathrm{ml}^{-1}$ with Ham's F-12 containing $15 \mathrm{mg} \mathrm{BSA} \mathrm{ml}{ }^{-1}$. The final concentration of absolute ethanol in progesterone-containing medium was $1 \%$. Two controls were included in this experiment: Ham's F-12 with $15 \mathrm{mg} \mathrm{BSA} \mathrm{ml}^{-1}$ and this medium plus $1 \%$ absolute ethanol. Twelve morphologically normal embryos were randomly assigned to each treatment. All subsequent media formulations used Ham's F-12 with $1.5 \mathrm{mg} \mathrm{BSA} \mathrm{ml}{ }^{-1}$ as the basal medium (HF-12).

\section{Dexamethasone}

Four concentrations $\left(0,10^{-8}, 10^{-7}\right.$ and $\left.10^{-6} \mathrm{~mol}^{-1}\right)$ of dexamethasone (Sigma) were prepared by diluting dexamethasone-absolute ethanol stock solutions with HF-12 and evaluated on 11-13 embryos per group.

\section{Retinoic acid}

Retinoic acid (Sigma) was dissolved in absolute ethanol and diluted to $0,10^{-8}, 10^{-7}$ and $10^{-6}$ mol $1^{-1}$ with HF-12. Twelve to 13 embryos were assigned to each treatment.

\section{Oestradiol}

Oestradiol (Sigma) was dissolved in absolute ethanol and diluted to four concentrations with HF-12 $\left(0,10^{-8}\right.$, $10^{-7}$ and $10^{-6} \mathrm{~g} \mathrm{ml}^{-1}$ ) and evaluated on 12-14 embryos per group.

\section{Phorbol myristate acetate and dbc AMP}

Experiment 1. Phorbol 12-myristate 13-acetate (Sigma) was dissolved in DMSO (Sigma) and diluted with HF-12 to a final concentration of $10 \mu \mathrm{g} \mathrm{ml}^{-1}$. Medium with $1 \%$ DMSO served as the control. Dibutyryl cAMP (Sigma) was diluted with HF-12 to 5 mmol $\mathrm{l}^{-1}$ and the corresponding control medium was HF-12. Seven to eight embryos were assigned to each of these four treatments.

Experiment 2. Phorbol 12-myristate 13-acetate was diluted to $100 \mathrm{ng} \mathrm{ml}^{-1}$ and dbcAMP was diluted to $0.5 \mathrm{mmol}$ $1^{-1}$. Two controls, HF-12 and HF-12 with $1 \%$ DMSO, were included in this experiment. Six to ten embryos were assigned to each treatment

Experiment 3. Phorbol 12-myristate 13-acetate was further diluted to $\mathrm{Ing} \mathrm{ml}^{-1}$ in $\mathrm{HF}-12$. Control medium contained $1 \%$ DMSO. Thirteen embryos were assigned to each treatment.

\section{Assay for PA activity}

Plasminogen-activator activities were determined by a caseinolytic assay as described by Kaaekuahiwi \& Menino (1990). Briefly, a casein-agar solution was prepared by combining $2 \%$ agarose (Sigma) with an equal volume of warmed $2 \%$ nonfat dry milk (Carnation Co., Los Angeles, CA) in 0.038 mol Tris(hydroxymethyl)-aminomethane $1^{-1}$, $0.1 \mathrm{~mol}$ glycine $\mathrm{l}^{-1}$ buffer containing $0.195 \mathrm{~g} \mathrm{CaCl}_{2} .2 \mathrm{H}_{2} \mathrm{O}^{-1}$ and $0.325 \mathrm{~g}$ sodium azide $\mathrm{l}^{-1}$. Fifteen millilitres of the warmed mixture were pipetted into $85 \times 65 \times 2 \mathrm{~mm}^{3}$ plastic diffusion plates and allowed to solidify at room temperature. Plasminogen-activator activities were determined by combining $15 \mu \mathrm{l}$ of $150 \mu \mathrm{g}$ human plasminogen $\mathrm{ml}^{-1}$ (Sigma) with $15 \mu$ l of either conditioned medium or $0,0 \cdot 001,0 \cdot 005,0 \cdot 01,0 \cdot 05$ and $0 \cdot 10$ milliunits urokinase $\mathrm{ml}^{-1}$ (E.C. 3.4.21.7; Sigma) as the standard and incubated for $15 \mathrm{~min}$ at $37^{\circ} \mathrm{C}$. Twenty-five microlitres of the incubated mixtures were aliquoted into $4 \mathrm{~mm}$ diameter wells cut in the casein-agar gel plate and incubated at room temperature for $24 \mathrm{~h}$. Plates were fixed for $15 \mathrm{~min}$ with $3 \%$ acetic acid and rinsed in tap water. The resultant caseinolytic zones were measured with an electronic digital caliper. Concentrations of PA in the conditioned media were determined from equation of the line calculations for caseinolytic ring diameter by log urokinase concentration. The amount of embryonic PA was determined by deducting the amount of PA in the medium without an embryo from the amount in the medium with an embryo for each $24 \mathrm{~h}$ interval. Plasminogen activator activity was expressed as milliunits PA $\times 10^{-4} \mathrm{ml}^{-1} \mathrm{~h}^{-1}$ per embryo.

\section{Statistical analyses}

With the exception of the PMA $\left(10 \mu \mathrm{g} \mathrm{ml}^{-1}\right.$ and $\left.100 \mathrm{ng} \mathrm{ml}^{-1}\right)$ and the dbcAMP $\left(5 \mathrm{mmol} \mathrm{l}^{-1}\right)$ treatments, statistical analyses were performed on data obtained from embryos that successfully hatched. Statistical comparisons were made by two-way analyses of variance where hormone treatment and time in culture were the main effects. Duncan's new multiple range test was used for multiple comparisons when appropriate. Analyses were performed using the NCSS statistical software program (Number Cruncher Statistical System, Version 4.1, 1984, J. L. Hintze, Kaysville, Utah).

\section{Results}

\section{Embryo recovery}

A total of 444 ova and embryos were collected from thirty-two cows of which $65 \%$ (287) were morphologically normal. Overall, $93.2 \%$ of these embryos completed hatching in vitro. 
Effects of hormones and inducers of intracellular messengers on PA production by cultured bovine embryos and on OED

\section{Progesterone}

Hatching occurred in 54 of 59 embryos $(92 \%)$. Because $1 \%$ absolute ethanol (Fig. la and b) had no effect $(P>0 \cdot 10)$ on PA production or OED, this final concentration was maintained for all other treatments using absolute ethanol as vehicle. Progesterone concentrations of $10^{-8}, 10^{-7}$ and $10^{-6} \mathrm{~g} \mathrm{ml}^{-1}$ affected neither PA production nor OED $(P>0 \cdot 10)$. However, duration of culture affected $(P<0.05)$ both PA production and OED. No interaction between time and concentration of hormone was observed $(P>0 \cdot 10)$. At the beginning of the culture PA production was low. PA production increased $(P<0.05)$ after $72 \mathrm{~h}$ of culture, reaching a maximum after $96 \mathrm{~h}$, and this rate of production was maintained thereafter. Overall embryo diameter increased with time in culture $(P<0.05)$, reached a maximum at $72 \mathrm{~h}$ and then declined $(P<0 \cdot 05)$.

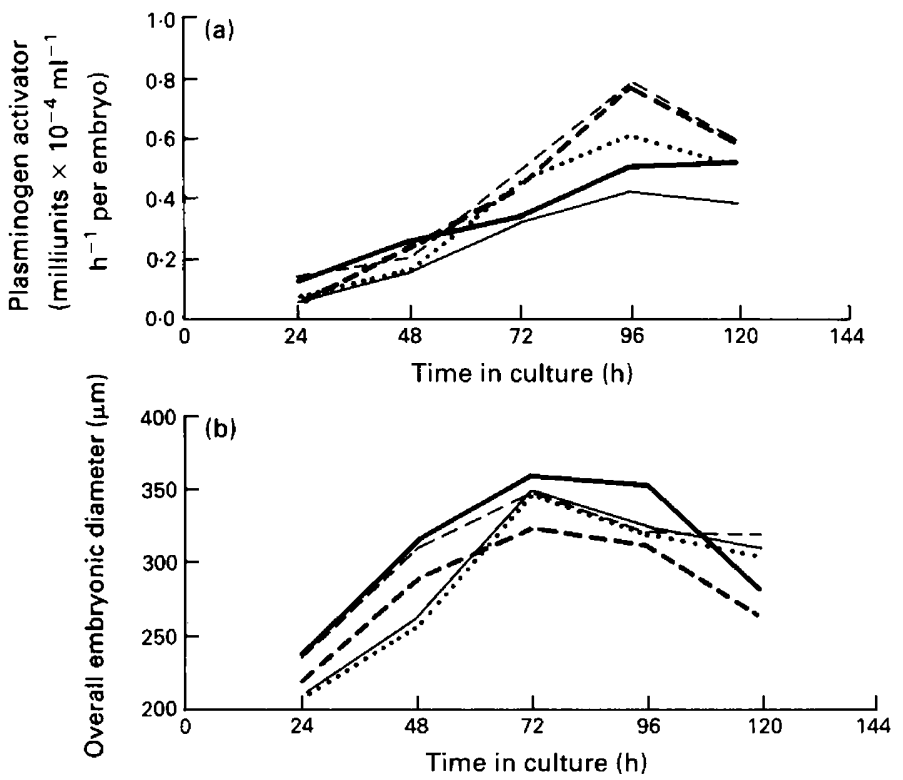

Fig. 1. (a) Plasminogen activator production and (b) overall embryonic diameter reached by bovine embryos cultured in Ham's F-12 with $15 \mathrm{mg}$ bovine serum albumin per ml containing 0 $(\square), 0$ plus ethanol $(---), 10^{-8}(-), 10^{-7}(\cdots \cdots)$ or $10^{-6}(---)$ g progesterone $\mathrm{ml}^{-1}$. Error mean squares for (a) and (b) are 0.222 and 8587 , respectively.

\section{Dexamethasone}

Hatching occurred in 44 of 46 embryos (96\%). Plasminogen-activator production and OED were not affected $(P>0 \cdot 10)$ by dexamethasone treatments (Fig. $2 \mathrm{a}$ and b). Plasminogen-activator production increased progressively, reached a maximum at $96 \mathrm{~h}$ and then decreased $(P<0.05)$. Similarly, OED increased $(P<0.05)$ during the first $48 \mathrm{~h}$, peaked at $72 \mathrm{~h}$ and then diminished. No interaction was detected $(P>0 \cdot 10)$ between concentration of dexamethasone used and time in culture.

\section{Retinoic acid}

Hatching occurred in 41 of 43 embryos $(93 \%)$. Retinoic acid did not affect $(P>0 \cdot 10)$ PA production or OED (Fig. 3a and b). Plasminogen-activator production and OED changed with time $(P<0 \cdot 01)$ but no interaction was observed between the main effects $(P>0 \cdot 10)$. After $72 \mathrm{~h}$ in culture plasminogen-activator production increased $(P<0.05)$ and remained high thereafter. 

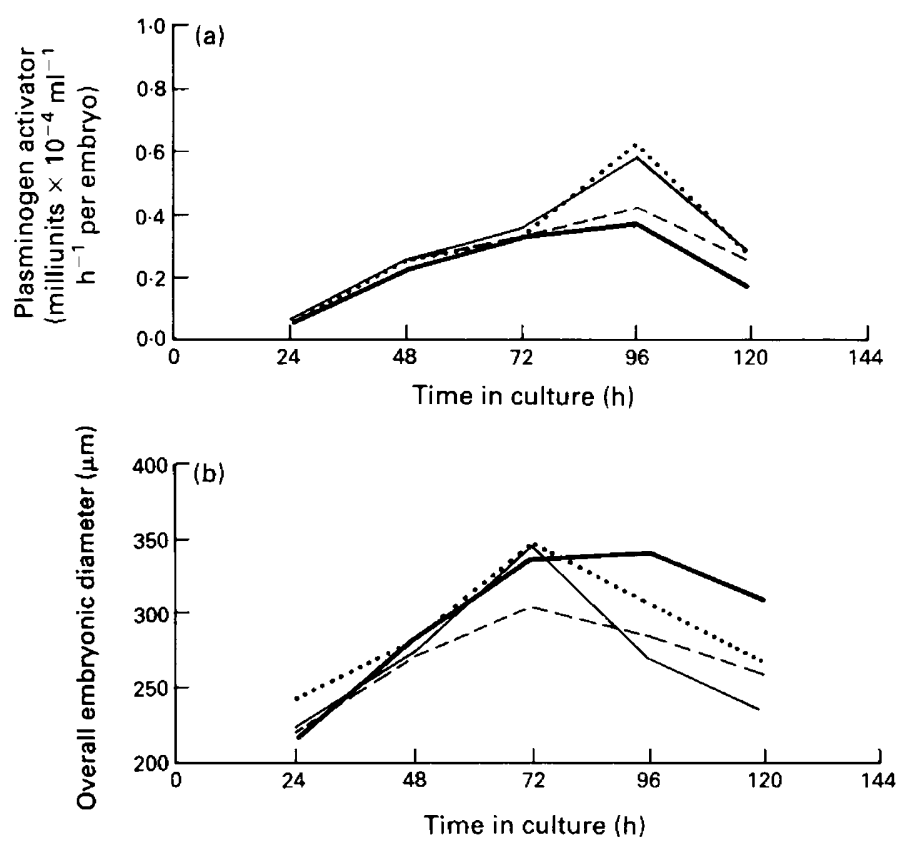

Fig. 2. (a) Plasminogen activator production and (b) overall embryonic diameter reached by bovine embryos cultured in Ham's F-12 with $1.5 \mathrm{mg}$ bovine serum albumin $\mathrm{ml}^{-1}$ containing 0 $(-), 10^{-8}(-), 10^{-7}(\cdots \cdots)$ or $10^{-6}(\cdots)$ mol dexamethasone $1^{-1}$. Error mean squares for (a) and (b) are 0.046 and 6166 , respectively.

Overall embryo diameter progressively increased $(P<0.05)$, reaching a maximum at $72 \mathrm{~h}$, then declined toward the end of culture $(P<0.05)$.

\section{Oestradiol}

Hatching occurred in 45 of 48 embryos $(94 \%)$. No effect was observed on PA production and OED $(P>0 \cdot 10)$ by the oestradiol treatments (Fig. 4a and b). In contrast, PA production and OED were affected by time in culture $(P<0 \cdot 01)$. The interaction between hormone treatment and time was not significant $(P>0 \cdot 10)$. Plasminogen-activator production remained unchanged for the first $48 \mathrm{~h}(P>0.05)$, then increased, reaching a plateau by $72 \mathrm{~h}(P<0.05)$. Overall embryo diameter increased during the first $48 \mathrm{~h}(P<0.05)$, reached a maximum between 72 and $96 \mathrm{~h}$ and then declined $(P<0.05)$.

\section{Phorbol myristate acetate and $\mathrm{dbcAMP}$}

Experiment 1. The percentage of embryos hatching in HF-12 or HF-12 with $10 \mu \mathrm{g} \mathrm{PMA} \mathrm{ml}^{-1}$, $5 \mathrm{mmol} \mathrm{dbcAMP} 1^{-1}$ or $1 \%$ DMSO was 100 (7 of 7 ), $0(0$ of 8$), 63$ (5 of 8 ), and 88 (7 of 8 ), respectively. Phorbol myristate acetate at $10 \mu \mathrm{g} \mathrm{ml}^{-1}$ caused embryos to degenerate and die within the first $24 \mathrm{~h}$. Dibutyryl cAMP also reduced the number of embryos hatching in vitro and caused embryo degeneration towards the end of culture $(P<0.05)$. Plasminogen-activator production was not affected $(P>0 \cdot 10)$ by dbcAMP (Fig. 5a). Production of PA increased $(P<0.01)$ from 24 to $48 \mathrm{~h}$, remained at a plateau until $96 \mathrm{~h}(P>0.05)$ and then decreased $(P<0.05)$. No interaction was observed between the two main effects $(P>0 \cdot 10)$. Overall embryo diameter decreased over time $(P<0 \cdot 10)$ and was reduced $(P<0.01)$ in the medium containing 5 mmol dbcAMP $1^{-1}$ (Fig. 5b). The interaction between time and treatment was also significant $(P<0.05)$. Compared with HF-12, DMSO decreased PA production $(P<0.01)$ only during the first $72 \mathrm{~h}$ of culture (Fig. 6a). Overall embryo diameter was not affected $(P>0 \cdot 10)$ by DMSO (Fig. 6b). 

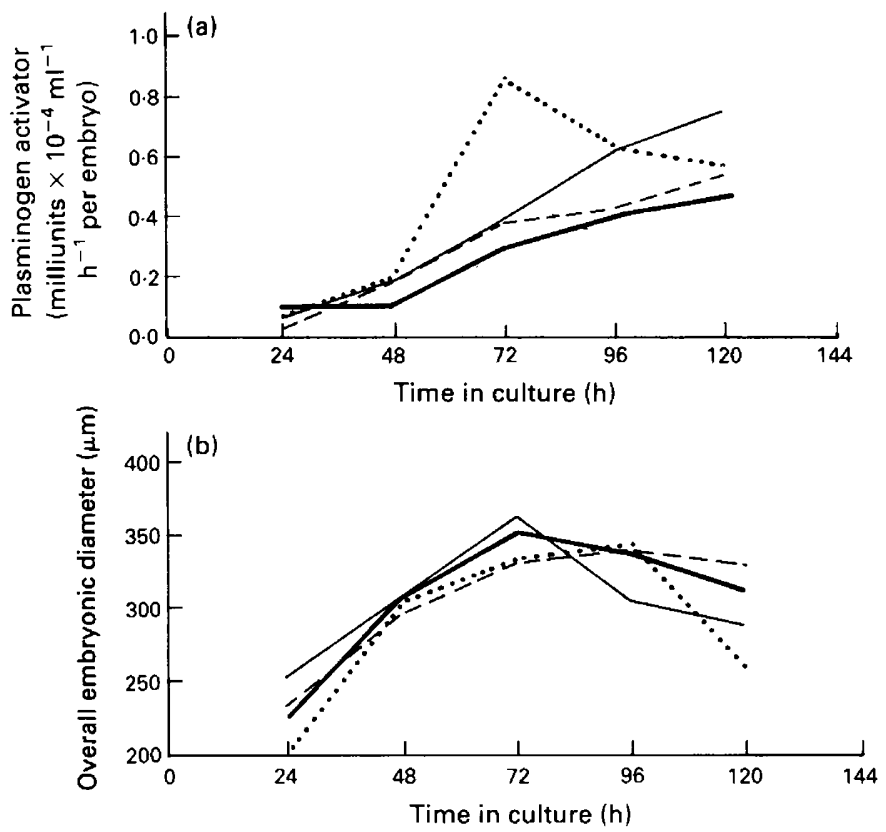

Fig. 3. (a) Plasminogen activator production and (b) overall embryonic diameter reached by bovine embryos cultured in Ham's F-12 with $1.5 \mathrm{mg}$ bovine serum albumin $\mathrm{ml}^{-1}$ containing 0 $(\longrightarrow), 10^{-8}(-), 10^{-7}(\cdots \cdots)$ or $10^{-6}(--)$ mol retinoic acid $\mathrm{l}^{-1}$. Error mean squares for (a) and (b) are 0.292 and 6377 , respectively.
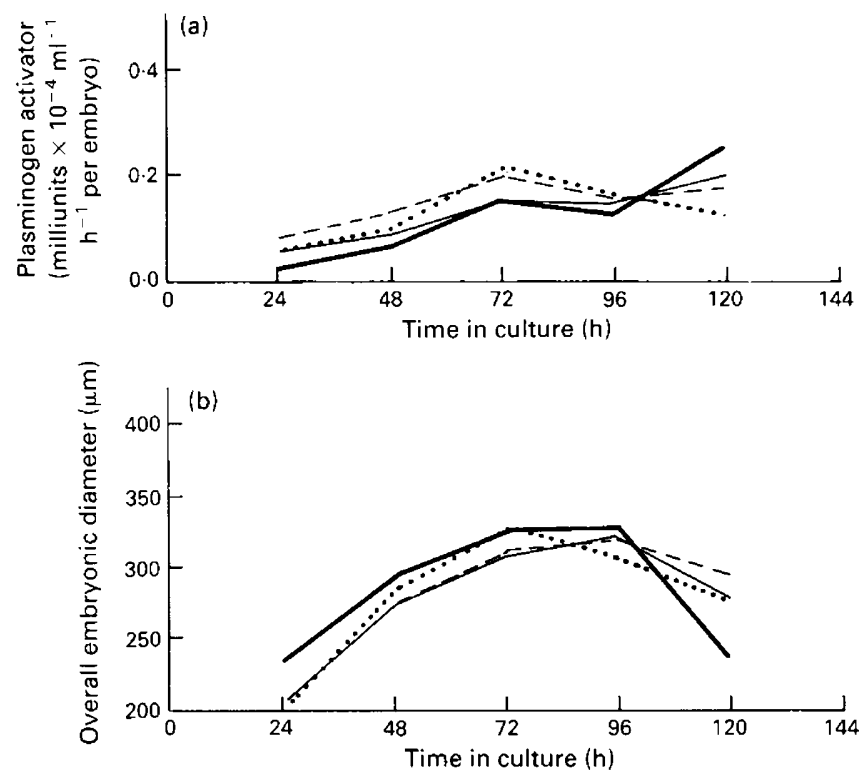

Fig. 4. (a) Plasminogen activator production and (b) overall embryonic diameter reached by bovine embryos cultured in Ham's F-12 with $1.5 \mathrm{mg}$ bovine serum albumin $\mathrm{ml}^{-1}$ containing 0 $(-), 10^{-8}(-), 10^{-7}(\cdots \cdots)$ or $10^{-6}(---) \mathrm{g}$ oestradiol $\mathrm{ml}^{-1}$. Error mean squares for (a) and (b) are 0.015 and 6377 , respectively. 

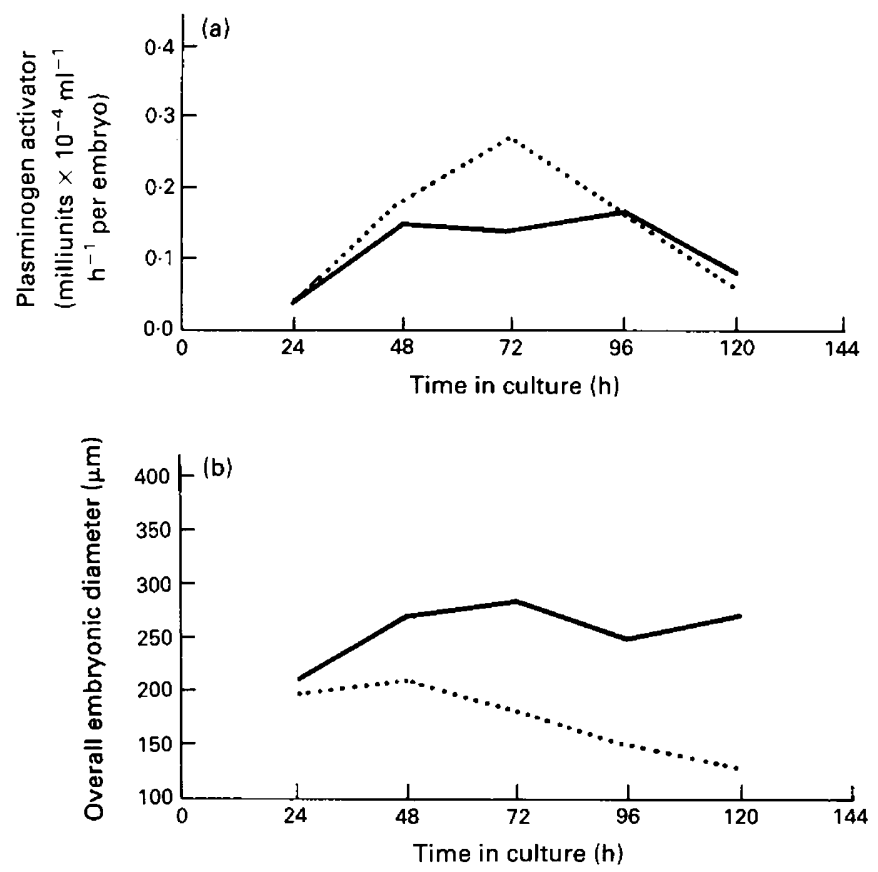

Fig. 5. (a) Plasminogen activator production and (b) overall embryonic diameter reached by bovine embryos cultured in Ham's F-12 with $1.5 \mathrm{mg}$ bovine serum albumin $\mathrm{ml}^{-1}$ containing 0 $(-)$ or $5(\cdots \cdots)$ mmol dibutyryl cAMP $~^{-1}$. Error mean squares for (a) and (b) are 0.008 and 2583 , respectively.
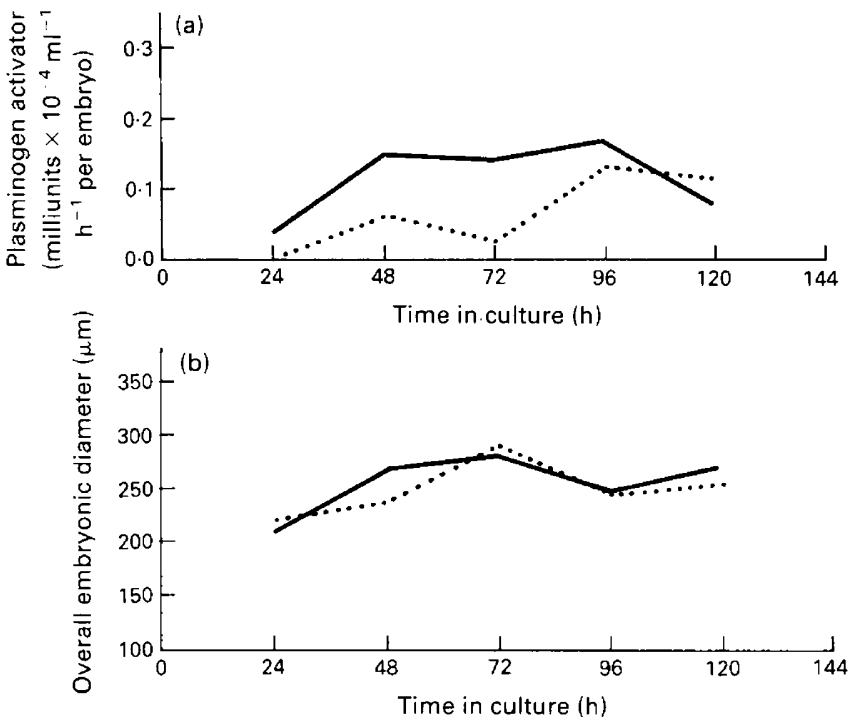

Fig. 6. (a) Plasminogen activator production and (b) overall embryonic diameter reached by bovine embryos cultured in Ham's F-12 with $1.5 \mathrm{mg}$ bovine serum albumin $\mathrm{ml}^{-1}$ containing 0 (-) or $1 \%(\cdots \cdots$.$) dimethyl sulfoxide. Error mean squares for (a) and (b) are 0.004 and 3180,$ respectively. 
Experiment 2. This experiment was designed to eliminate the deleterious effects of the high concentrations of PMA and dbcAMP observed in the first experiment. The percentage of embryos hatching in HF- 12 or HF- 12 with $100 \mathrm{ng} \mathrm{PMA} \mathrm{m}{ }^{-1}, 0.5 \mathrm{mmol} \mathrm{dbcAMP}^{-1}$ or $1 \%$ DMSO was 80 (8 of 10$), 17$ ( 1 of 6), 90 ( 9 of 10) and 71 ( 5 of 7), respectively. As evidenced by the reduced incidence of hatching, embryo development in medium with $100 \mathrm{ng} \mathrm{PMA} \mathrm{ml}^{-1}$ was suppressed compared with medium with DMSO $(P<0.01)$. Plasminogen-activator production was not affected by $0.5 \mathrm{mmol} \mathrm{dbcAMP} 1^{-1}(P>0 \cdot 10)$, but was affected by time, increasing $(P<0.05)$ by $48 \mathrm{~h}$, remaining unchanged until $96 \mathrm{~h}$ and then declining (Fig. 7a). In contrast, OED decreased $(P<0.05)$ in embryos cultured in 0.5 mmol dbcAMP $1^{-1}$, although duration of culture and the interaction were not significant (Fig. 7b). The results obtained for the effects of DMSO on PA production and OED were similar to those presented in Expt 1.
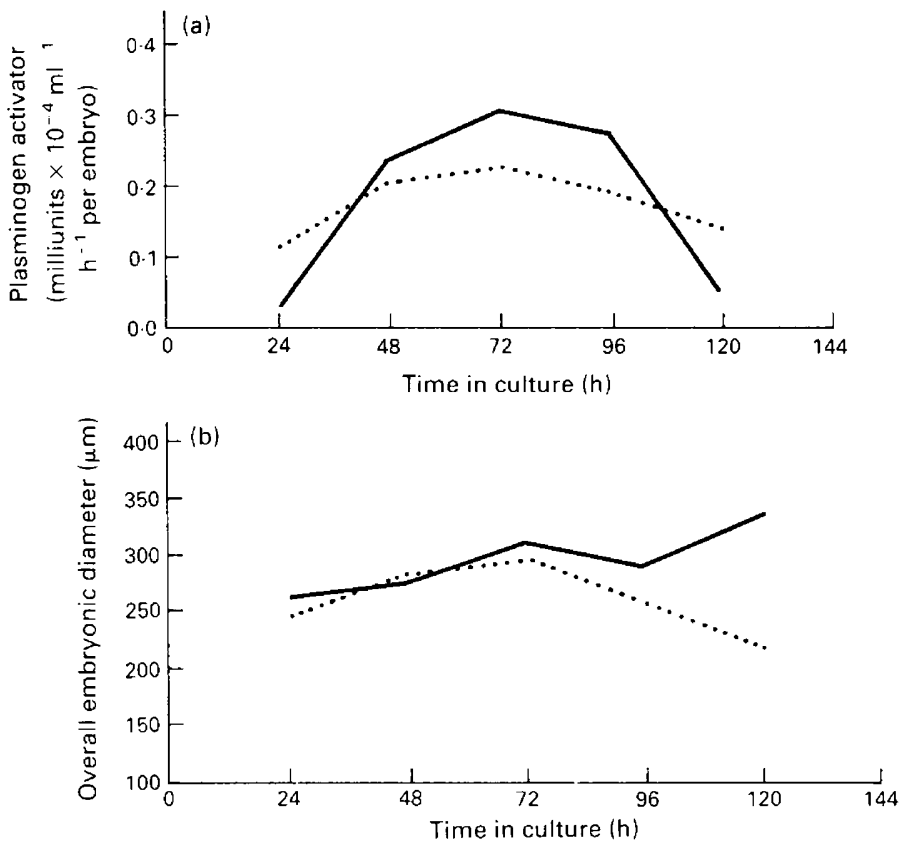

Fig. 7. (a) Plasminogen activator production and (b) overall embryonic diameter achieved by bovine embryos cultured in Ham's F-12 with $1.5 \mathrm{mg}$ bovine serum albumin $\mathrm{ml}^{-1}$ containing 0 $(\longrightarrow)$ or $0.5(\cdots \cdots$.$) mmol dibutyryl cAMP 1^{-1}$. Error mean squares for (a) and (b) are 0.027 and 5802 , respectively.

Experiment 3. The percentage of embryos hatching in HF-12 with $1 \mathrm{ng} \mathrm{PMA} \mathrm{ml}{ }^{-1}$ and $1 \% \mathrm{DMSO}$, and HF-12 with $1 \%$ DMSO was 92 (12 of 13) and 92 (12 of 13), respectively. The toxic effect of PMA on embryos observed during the previous experiments were eliminated in this experiment. Phorbol myristate acetate did not $(P>0 \cdot 10)$ affect PA activity (Fig. 8a), but did increase OED $(P<0 \cdot 05)$ (Fig. $8 \mathrm{~b})$. Plasminogen-activator production did not increase $(P>0.05)$ during the first $72 \mathrm{~h}$ but then increased to a plateau at $96 \mathrm{~h}(P>0.05)$ (Fig. 8a). Overall embryo diameter increased $(P<0.05)$ at $48 \mathrm{~h}$, stabilized between 72 and $96 \mathrm{~h}$, then decreased $(P<0.05)$ (Fig. 8b). No interaction between treatment and time in culture was observed with regard to PA production and OED.

\section{Discussion}

In this study, several known modulators of PA in other systems have been evaluated in cultured day 8 bovine embryos. Oestradiol increases PA activity in human breast carcinoma cell lines 

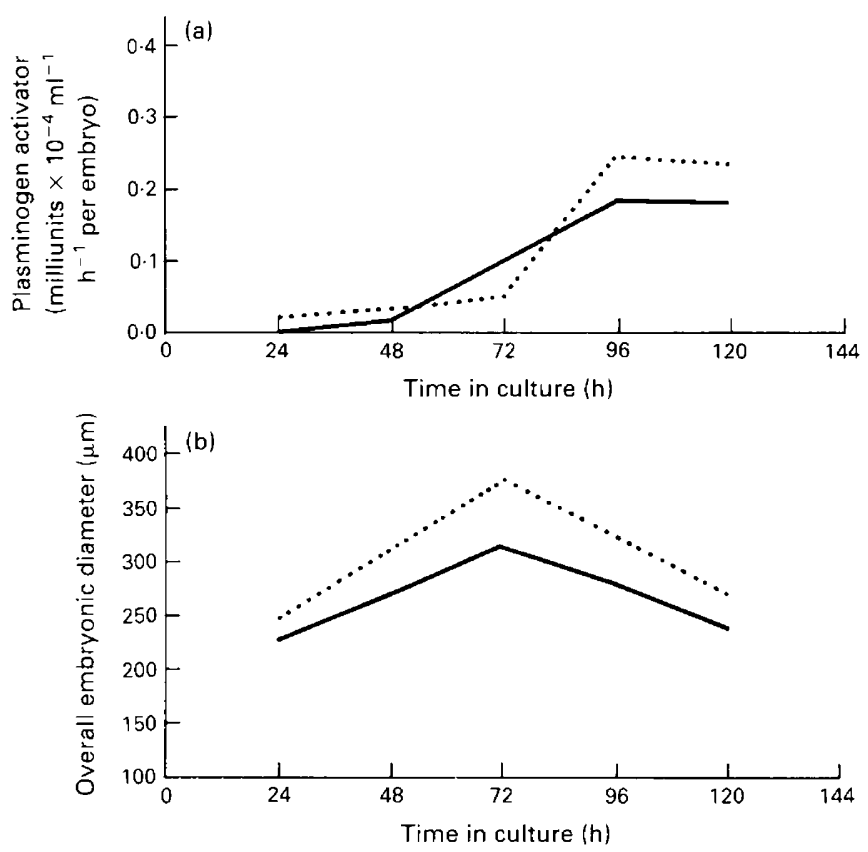

Fig. 8. (a) Plasminogen activator production and (b) overall embryonic diameter achieved by bovine embryos cultured in Ham's F-12 with $1.5 \mathrm{mg}$ bovine serum albumin $\mathrm{ml}^{-1}$ containing $1 \%(-)$ dimethyl sulfoxide or $1 \%(\cdots \cdots)$ dimethyl sulfoxide and 1 ng phorbol 12 -myristate 13 -acetate $\mathrm{ml}^{-1}$. Error mean squares for (a) and (b) are $0 \cdot 013$ and 5945, respectively.

MCF-7 (Dickerman et al., 1989); retinoic acid stimulates PA production in chick embryo fibroblasts and muscle cells (Wilson \& Reich, 1978; Miskin et al., 1978); progesterone and dexamethasone have been shown to stimulate the production of an inhibitor that decreases plasminogen activation in several tissues including porcine endometrium (Fazleabas et al., 1982), rat granulosa cells (Harlow et al., 1987) and bovine Sertoli cells (Coombs \& Jenkins, 1988). However, in the present study, neither progesterone, oestradiol, dexamethasone nor retinoic acid affected the production of PA by cultured bovine embryos. Furthermore, these modulators did not affect overall embryo diameter nor hatching rate. There are three possible explanations for the lack of effect of these hormones on preimplantation bovine embryos. The first is that hormones affect embryos indirectly through the stimulation of genital tract secretions; the second is that the embryo synthesizes its own hormones, which may act in autocrine fashion to regulate early developmental events (Paria \& Dey, 1990); and the third is that the embryo has the ability to achieve normal development to the blastocyst stage in vitro or in the oviduct of other species regardless of their hormonal status, signifying a considerable autonomy in early embryonic development (Betteridge $\&$ Flechon, 1988). The normal growth of cultured bovine embryos observed in this study supports the existence of an endogenous control mechanism that contributes to the independence of the embryo from maternal hormones during in vitro development.

Although PA production by cultured bovine embryos was not affected by the hormone treatments, a substantial and consistent increase in this enzyme during culture was observed in all experiments. Plasminogen-activator production was relatively low during the first $48 \mathrm{~h}$ of culture, increasing at $72 \mathrm{~h}$ to reach a maximum by $96 \mathrm{~h}$ and then remaining at this rate. Some slight deviations from this pattern were noted with dexamethasone, where PA production decreased toward the end of culture, and with oestradiol, where maximum PA production was reached at $72 \mathrm{~h}$. PA production by embryos cultured in the presence and absence of oestradiol was lower than 
that observed in the other experiments. Kaaekuahiwi \& Menino (1990) observed that the source of the embryos significantly affected OED and PA production by bovine embryos developing in vitro. As different cows were used as embryo donors for every experiment, it is possible that variation in PA production between experiments may be due to differences in embryo donors.

Dibutyryl cAMP, a known inducer of cAMP-dependent protein kinase A, has been found to stimulate the production of PA in various types of cell (Beers et al., 1975; Hettle et al., 1986; Queenan et al., 1987) by promoting the transcriptional activity of the PA gene (Nagamine et al., 1983; Roesler et al., 1988). In this study, although dbcAMP did not affect PA production, a progressive decrease in OED was observed. This inhibitory effect persisted, but to a lesser extent, when the dbcAMP concentration was reduced tenfold. Fisher \& Gunaga (1975) have reported that the development of mouse blastocysts was retarded when cAMP accumulation was induced by theophylline, an inhibitor of intracellular breakdown of cAMP. High concentrations of cAMP are generally associated with inhibition of cellular proliferation (Bombik \& Burger, 1973), presumably through inhibition of the rate of replication (Thomas et al., 1973). In contrast, Manejawala et al. (1986) and Manejawala \& Schultz (1989) demonstrated that cAMP analogues, which activate the cAMP-dependent protein kinase, stimulate the rate of blastocoel expansion and $\mathrm{Na}^{+}$uptake by mouse preimplantation embryos, suggesting a possible function for cAMP in blastocoel formation. The discrepancy between the observations of Manejawala et al. (1986) and Manejawala \& Schultz (1989) and our results could be explained by differences in the duration of culture. Whereas embryos in this study were cultured for 5 days, Manejawala et al. (1986) and Manejawala \& Schultz (1989) incubated embryos for only $8 \mathrm{~h}$. Furthermore, our results with bovine embryos demonstrated that dbcAMP was without effect on OED during the first $24 \mathrm{~h}$ and that the inhibitory effect of dbcAMP did not appear until the later stages of culture.

Phorbol 12-myristate 13-acetate, a potent tumour promotor, has been found to enhance PA activity in many cell types (Wigler et al., 1970; Vassalli et al., 1977; Quigley, 1979), through the activation of phospholipid-dependent protein kinase C (Castagna et al., 1982). The possibility that the embryo uses protein kinase $\mathrm{C}$ in regulating PA production was therefore investigated. Although PMA at a concentration not lethal to bovine embryos inhibited PA production during the first $72 \mathrm{~h}$ of culture, this inhibitory effect was due to DMSO which was used to dissolve the PMA in the culture medium. Results from the first and second experiments comparing the effect of DMSO to the control treatment suggests that this polar solvent inhibited PA production, particularly during the first $72 \mathrm{~h}$ of culture. Phorbol myristate acetate itself neither potentiated nor decreased PA production. Carlsen (1987), however, found that DMSO concentrations up to $2 \cdot 5 \%$ greatly stimulated the production of PA in Chinese hamster ovary cells, and that new protein and RNA synthesis were required for this process. The inhibitory effect of DMSO on PA production observed in this study was not accompanied by changes in embryo viability. The reason for this inhibitory effect of DMSO requires further investigation. Embryos cultured in the presence of high concentrations of PMA failed to hatch, showed signs of degeneration within $24 \mathrm{~h}$, and completely degenerated by $72 \mathrm{~h}$ of culture, whereas PMA at low concentrations significantly stimulated embryonic diameter. Phorbol esters have been shown to stimulate RNA synthesis (Sivak \& Van Duuren, 1970), increase cell division (Driedger \& Blumberg, 1977), enhance protein synthesis (Hiwasa et al., 1982), and increase the specific activity of cell membrane-associated $\mathrm{Na}^{+}-\mathrm{K}^{+}-\mathrm{ATPase}$ activity (Sivak et al., 1972). Ultimately, these processes would lead to an increase in embryonic diameter.

The physiological role of PA in early bovine embryogenesis is not known. Endodermal cells of the bovine embryo begin to migrate on day 8 and their migration involves the interaction with an extracellular matrix (Betteridge \& Flechon, 1988). Plasminogen activator, particularly uPA, has been implicated in the migration of cultured cells (Ossowski et al., 1975) as well as parietal endoderm in mouse embryos (Strickland et al., 1976). Accordingly, PA released by bovine embryos may play a role in facilitating cellular migration during this preimplantation period. Hatching also occurs on day 10 and PA may be involved in inducing a sublysis of the zona pellucida to allow the blastocyst to escape. 
In conclusion, bovine preimplantation embryos developing in vitro release an appreciable amount of PA, which is neither dependent upon nor influenced by hormonal regulation. With the exception of PMA and dbcAMP, the hormones tested here showed no effect on overall embryonic diameter. Further research is required to elucidate the function of PA during the early stages of bovine embryo development.

The authors wish to thank R. Miller and D. Ramstad of the Oregon State University Beef Cattle Center for their cooperation and M. Sharp and D. Martin for typing the manuscript. This research was supported by USDA grant No. 87-CRCR-1-2536. Technical Paper No. 9636, Oregon Agricultural Experiment Station.

\section{References}

Astrup, T. (1978) Fibrinolysis, an overview. In Progress in Chemical Fibrinolysis and Thrombolysis, Vol. 3, pp. 1-97. Eds J F. Davidson, R. M. Rowan, M. M. Saramaria \& P. C. Desnoyers. Raven Press, New York.

Axelrod, H.R. (1985) Altered trophoblast functions in implantation-defective mouse embryo. Developmental Biology 108, 185-190.

Beers, W.H., Strickland, S. \& Reich, E. (1975) Ovarian plasminogen activator: relationship to ovulation and hormonal regulation. Cell 6, 387-394.

Betteridge, K.J. \& Flechon, J.E. (1988) The anatomy and physiology of pre-attachment bovine embryos. Theriogenology 29, 154-187.

Blasi, F., Vassalli, J-D. \& Dano, K. (1987) Urokinasetype plasminogen activator: proenzyme, receptor and inhibitors. Journal of Cell Biology 104, 801-804.

Bombik, B.M. \& Burger, M.M. (1973) c-AMP and the cell cycle: inhibition of growth stimulation. Experimental Cell Research 20, 88-94.

Canipari, R. \& Strickland, S. (1986) Studies on the hormonal regulation of plasminogen activator production in the rat ovary. Endocrinology 118, 1652-1659.

Carlsen, S.A. (1987) Stimulation of plasminogen activator production by dimethyl sulfoxide in Chinese hamster ovary cells. Biochemistry and Cell Biology 65, 710-716.

Castagna, M., Takai, Y., Kaibuchi, K., Sano, K., Kikkawa, U. \& Nishizuka, Y. (1982) Direct activation of calcium-activated, phospholipid-dependent protein kinase by tumor-promoting phorbol esters. Journal of Biological Chemistry 257, 7847-7851.

Coombs, R.J. \& Jenkins, N. (1988) Characterization of a plasminogen activator inhibitor induced by glucocorticoids in immature bovine Sertoli cellenriched cultures. Journal of Endocrinology 117, $69-74$.

Coombs, R.J., Ellison, J., Woods, A. \& Jenkins, N. (1988) Only tissue-type plasminogen activator is secreted by immature bovine Sertoli cell-enriched cultures. Journal of Endocrinology 117, 63-67.

Dano, K., Androesen, P.A., Grondahl-Hansen, J., Kristensen, P., Nielsen, L.S. \& Skriver, L. (1985) Plasminogen activators, tissue degradation, and cancer. Advances in Cancer Research 44, 139-266.

Dickerman, H.W., Martinez, H.L., Seeger, J.I. \& Kumar, S.A. (1989) Estrogen regulation of human breast cancer cell line MCF-7 tissue plasminogen activator. Endocrinology 125, 492500.
Driedger, P.E. \& Blumberg, P.M. (1977) The effect of phorbol diesters on chick embryo fibroblasts. Cancer Research 3257-3265.

Dulbecco, R. \& Vogt, M. (1954) Plaque formation and isolation of pure lines with poliomyelitis viruses. Journal of Experimental Medicine 99, 167-182.

Fazleabas, A.T., Bazer, F.W. \& Roberts, R.M. (1982) Purification and properties of a progesteroneinduced plasmin/trypsin inhibitor from uterine secretion of pigs and its immunocytochemical localization in the pregnant uterus. Journal of Biological Chemistry 257, 6886-6897.

Fazleabas, A.T., Geisert, R.D., Bazer, F.W. \& Roberts, R.M. (1983) Relationship between release of plasminogen activator and estrogen by blastocysts and secretion of plasmin inhibitor by uterine endometrium in the pregnant pig. Biology of Reproduction 29, 225-238.

Finlay, T.H., Katz, J., Levita, M., Nathoo, S.A. \& Seiler, S. (1983) Estrogen-stimulated uptake of plasminogen by the mouse uterus. Endocrinology 112, 856-861.

Fisher, D.L. \& Gunaga, K.P. (1975) Theophylline induced variations in cyclic AMP content of the superovulated preimplantation mouse embryo. Biology of Reproduction 12, 471-476.

Harlow, C.R., Coombs, R.J., Hodges, J.K. \& Jenkins, N. (1987) Modulation of plasminogen activation by glucocorticoid hormones in rat granulosa cell. Journal of Endocrinology 114, 207--212.

Harpel, P., Bang, N.U., Hamburger, F. \& Treger, A. (1966) Plasminogen activator in mouse uterine fiuid: its suppression by estradiol and progresterone. Proceedings of the Society of Experimental Biology and Medicine 122, 1192-1195.

Hettle, J.A., Waller, E.K. \& Fritz, I.B. (1986) Hormonal regulation alters the type of plasminogen activator produced by Sertoli cells. Biology of Reproduction 34, 895-904.

Hiwasa, T., Fujimura, S. \& Sakiyama, S. (1982) Tumor promotors increase the synthesis of a 32,000-dalton protein in BALB/c 3T3 cells. Proceedings of the National Academy of Sciences USA 79, 1800-1804.

Kaaekuahiwi, M.A. \& Menino, A.R. (1990) Relationship between plasminogen activator production and bovine embryo development in vitro. Journal of Animal Science 68, 2009-2014.

Lacroix, M., Parvienen, M. \& Fritz, I. (1981) Localization of testicular plasminogen activator in discrete positions (stages VII and VIII) of the seminiferous tubule. Biology of Reproduction 25, 143-146. 
Liedholm, P. \& Astedt, B. (1975) Fibrinolytic activity of the rat ovum, appearance during tubual passage and disappearance at implantation. International Journal of Fertility 20, 24-26.

Lindner, G.M. \& Wright, R.W. (1983) Bovine embryo morphology and evaluation. Theriogenology $\mathbf{2 0}$, 407-416.

Manejawala, F.M. \& Schultz, R.M. (1989) Blastocoel expansion in the preimplantation mouse embryo: stimulation of sodium uptake by cAMP and possible involvement of cAMP-dependent protein kinase. Developmental Biology 136, 560-563.

Manejawala, F.M., Kajie, T. \& Schultz, R.M. (1986) Development of activatable adenylate cyclase in preimplantation mouse embryos and a role of cyclic AMP in blastocoel formation. Cell 46, 95103.

Marzowski, J., Sylvester, S.R., Gilmont, R.R. \& Griswold, M.D. (1985) Isolation and characterization of Sertoli cell plasma membranes and associated plasminogen activator activity. Biology of Reproduction 32, 1237-1245.

Menino, A.R. \& Williams, J.S. (1987) Activation of plasminogen by the early bovine embryo. Biology of Reproduction 36, 1289-1295.

Menino, A.R., Dyk, A.R., Gardiner, C.S., Grobner, M.A., Kaaekuahiwi, M.A. \& Williams, J.S. (1989) The effects of plasminogen on in vitro ovine embryo development. Biology of Reproduction 41, 899-905.

Miskin, R., Easton, T.G. \& Reich, E. (1978) Plasminogen activator in chick embryo muscle cells: induction of enzyme by RSV, PMA and retinoic acid. Cell 15, 1302-1312.

Mullins, D.E., Bazer, F.W. \& Roberts, R.M. (1980) Secretion of a progesterone-induced inhibitor of plasminogen activator by the porcine uterus. Cell 20, 865-872.

Nagamine, Y., Sudol, M. \& Reich, E. (1983) Hormonal regulation of plasminogen activator $m$ RNA production in porcine kidney cells. Cell 32, 1181-1190.

Opdenakker, G., Ashino-Fuse, H., VanDamme, J., Billiau, A. \& DeSomer, P. (1983) Effect of 12-O-tetradecanoylphorbol-13-acetate on the production of mRNAs for human tissue-type plasminogen activator. European Journal of Biochemistry 131, 481-487.

Ossowski, L., Quigley, J.P. \& Reich, E. (1975) Plasminogen, a necessary factor for cell migration in vitro. In Proteases and Biological Control, pp. 901-913. Eds E. Reich, D. B. Rifkin \& E. Shaw. Cold Spring Harbor Laboratory, New York.

Paria, B. C. \& Dey, S. K. (1990) Preimplantation embryo development in vitro: cooperative interactions among embryos and role of growth factors. Proceedings of the National Academy of Sciences USA 87, 4756-4760.

Queenan, Jr, J.T., Kao, L-C., Arboleda, C.E., UlloaAquirre, A., Golos, T.G., Cines, D.B. \& Strauss, III, J.F. (1987) Regulation of urokinase-type plasminogen activator production by cultured human cytotrophoblasts. Journal of Biological Chemistry 262, 10903-10906.

Quigley, J.P. (1979) Phorbol ester-induced morphological changes in transformed chick fibroblasts: evidence for direct catalytic involvement of plasminogen activator. Cell 17, 131-141.
Reich, R., Misken, R. \& Tsafriri, A. (1985) Follicular plasminogen activator: involvement in ovulation. Endocrinology 116, 516-521.

Roesler, W.J., Vandenbark, G.R. \& Hanson, R.W. (1988) Cyclic AMP and the induction of eukaryotic gene transcription. Journal of Biological Chemistry 263, 9063-9066.

Santell, L. \& Levin, E.G. (1988) Cyclic AMP potentiates phorbol ester stimulation of tissue plasminogen activator release and inhibits secretion of plasminogen activator inhibitor-1 from human endothelial cells. Journal of Biological Chemistry 263, 16802-16808.

Sappino, A.-P., Huarte, J., Belin, D. \& Vassalli, J-D. (1989) Plasminogen activators in tissue remodeling and invasion: mRNA localization in mouse ovaries and implanting embryos. Journal of Cell Biology 109, 2471-2479.

Sherman, M.I. (1980) Studies on the temporal correlation between secretion of plasminogen activator and stages of early mouse embryogenesis. Oncodevelopmental Biology and Medicine 1, 7-17.

Sherman, M.I., Strickland, S. \& Reich, E. (1976) Differentiation of early mouse embryonic and teratocarcinoma cells in vitro: plasminogen activator production. Cancer Research 36, 4208-4216.

Sivak, A. \& Van Duuren, B.L. (1970) RNA synthesis induction by a tumor promoter. Cancer Research 30, 1203-I 205.

Sivak, A., Mossman, B.T. \& Van Durren, B.L. (1972) Activation of cell membrane enzymes in the stimulation of cell division. Biochemical and Biophysical Research Communications 46, 606-609.

Strickland, S. \& Beers, W.H. (1976) Studies on the role of plasminogen activator in ovulation. In vitro response of granulosa cells to gonadotropins, cyclic nucleotides, and prostaglandins. Journal of Biological Chemistry 251, 5694-5702.

Strickland, S. \& Mahdavi, V. (1978) The induction of differentiation in teratocarcinoma stem cells by retinoic acid. Cell 15, 393-403.

Strickland, S., Reich, E. \& Sherman, M.I. (1976) Plasminogen activator in early embryogenesis: enzyme production for trophoblast and parietal endoderm. Cell 9, 231-240.

Thomas, D.B., Medley, G. \& Lingwood, C.A. (1973) Growth inhibition of murine tumor cells, in vitro, by puromycin, $\left({ }^{6} \mathrm{~N}\right) \mathrm{O}^{2 \prime}$-dibutyryl $3^{\prime}, 5^{\prime}$-adenosine monophosphate or adenosine. Journal of Cell Biology 57, 397-405

Vassalli, J-D., Hamilton, J. \& Reich, E. (1977) Macrophage plasminogen activator: induction by concanavalin $\mathrm{A}$ and phorbol myristate acetate. Cell 11, 695-705

Wigler, M., Defeo, D. \& Weinstein, E. (1970) Induction of plasminogen activator in cultured cells by macrocyclic plant dieterpene esters and other agents related to tumor promotion. Cancer Research 38, 1434-1437.

Wilson, E.L. \& Reich, E. ( 1978) Plasminogen activator in chick fibroblasts: induction of synthesis by retinoic acid; synergism with viral transformation and phorbol ester. Cell 15, 385-392. 